\title{
EFFECTS OF TRIIODOTHYRONINE AND OTHER THYROXINE ANALOGUES ON THYROXINE-BINDING IN HUMAN SERUM ${ }^{1}$
}

\author{
By JACOB ROBBINS 2 AND J. E. RALL ${ }^{3}$ \\ (From the Sloan Kettering Institute for Cancer Research, Memorial Center for Cancer and \\ Allied Diseases, New York, N. Y.)
}

(Submitted for publication February 18, 1955; accepted April 20, 1955)

The strong affinity between thyroxine and the specific thyroxine-binding protein (TBP) of human serum (1) is apparent from, a) the inability to remove more than small amounts of thyroxine from the serum by prolonged dialysis (2), and b) the effectiveness with which TBP competes with albumin for available thyroxine in serum, despite its much smaller concentration. Thyroxine bound to $\mathrm{TBP}$ is, nevertheless, free to exchange with thyroxine added to serum in vitro (3). Thus, when endogenous serum thyroxine has been labeled with $\mathrm{I}^{\mathbf{1 3 1}}$, the addition of excess quantities of unlabeled thyroxine to such serum will cause a displacement of thyroxine- $\mathrm{I}^{131}$ from TBP. It may be expected that the addition to such serum of any substance capable of competing with thyroxine for its binding sites on the specific protein, would cause a similar displacement of thyroxine-I ${ }^{131}$.

Earlier reports (4-6) have revealed that triiodothyronine has the ability to displace thyroxine from TBP. The present study represents an attempt to quantitate this effect, and to compare, in this way, the affinity of a series of thyroxine analogues for TBP.

\section{MATERIALS AND METHODS}

Sera from three healthy young adults (one female, two males) were obtained after overnight fasts, and were stored in the frozen state until used. The 14 analogues of thyroxine which were studied are listed in Table I, together with their sources of supply.4 Each

1 This work was supported by a grant from the Damon Runyon Memorial Fund for Cancer Research, a grant from the American Cancer Society, and a contract with the Atomic Energy Commission, No. AT(30-1)-910.

2 Present address: National Institute of Arthritis and Metabolic Diseases, National Institutes of Health, Bethesda, Maryland.

3 Alfred P. Sloan Foundation Scholar.

4 The authors are indebted to these sources for their generosity in making the compounds available for this study. compound was dissolved in $n$-butanol at a concentration of 20 or 40 micrograms per $\mathrm{ml}$. In the case of diiodothyronine and triiodothyronine, solution was favored by the addition of 0.3 per cent by volume of $2 \mathrm{~N}$ ammonium hydroxide. Three of the compounds (O-p-nitrobenzylL-tyrosine, and the $3^{\prime}, 5^{\prime}$-dinitro and $3^{\prime}, 5^{\prime}, 3,5$-tetranitro analogues of thyroxine) were incompletely dissolved, but a fine, and apparently homogeneous, suspension was obtained prior to the removal of aliquots.

Three batches of L-thyroxine, labeled with I ${ }^{131}$, and dissolved in $n$-butanol were used.5 Chromatographic analyses of these preparations (3) revealed that thyroxine-I ${ }^{131}$ comprised from 72 to 86 per cent (mean = 80 per cent) of the total radioactivity. From 3 to 5 per cent behaved like iodide, and from 10 to 25 per cent was due to contaminants of unknown nature.

Appropriate quantities of the L-thyroxine-I131 solution and each of the thyroxine analogue solutions were combined so as to produce fixed concentrations of thyroxine in the presence of varying concentrations of analogue. These mixtures were evaporated to dryness in vacuo without heating. Serum was then added, allowed to stand for 15 to 20 hours at $4^{\circ} \mathrm{C}$., and then stored in the frozen state until used.

The concentration of thyroxine in the serum mixtures was determined by iodine analysis as previously described (3). Similar analysis was made for those analogues which contained iodine. In the case of the remaining analogues, the measured concentration (weight plus dilution factors) was used. Recovery of thyroxine-I131 after drying was assessed by radioactivity measurements as previously described (3), and it was assumed that identical recoveries pertained to the thyroxine analogues in each instance. These recoveries ranged from 68 to 115 per cent, but were usually between 85 and 100 per cent (mean $=93$ per cent). The concentrations of thyroxine and analogues employed are indicated in Table I.

Each serum mixture was subjected to zone electrophoresis in filter paper at $\mathrm{pH} 8.6$ (barbital buffer, ionic strength 0.1 , and the distribution of radioiodine among the various serum protein components were determined. The techniques employed have been described elsewhere (3).

${ }^{5}$ L-thyroxine was obtained through the courtesy of Smith, Kline and French Laboratories, Philadelphia, $\mathrm{Pa}$., and was labeled with I $^{131}$ by Abbott Laboratories, Oak Ridge, Tenn. 


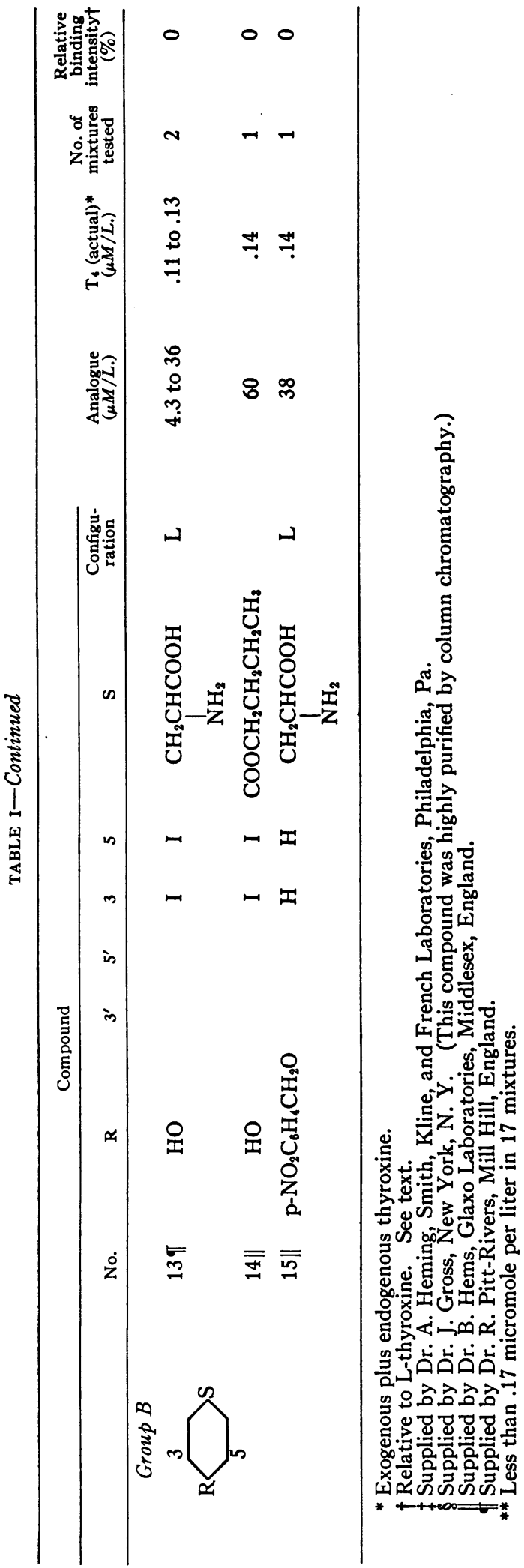

\section{RESULTS}

Electrophoretic distribution of radioiodine in serum containing a constant, small amount of $\mathrm{L}$ thyroxine- $\mathrm{I}^{131}$ and increasing concentrations of $\mathrm{L}$ triiodothyronine is illustrated in Figure 1. At high triiodothyronine concentrations, thyroxine$\mathrm{I}^{131}$ is displaced from the alpha globulin area, and becomes associated with the other serum protein components, particularly with albumin. These results are analogous to those obtained when excess quantities of L-thyroxine are added to serum (3), but the molar concentration of L-triiodothyronine required to produce a given displacement is greater than in the case of thyroxine.

L-TRIOOOTHMRONNE + L-THMRONE - 131

N NORMAL SERUM

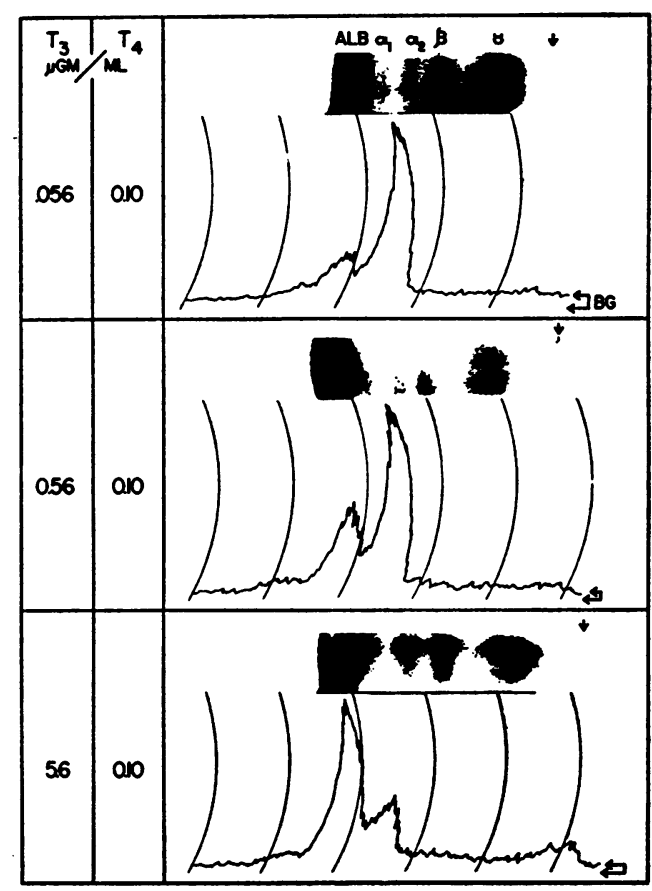

Fig. 1. The Effect of Increasing Concentrations of L-Triodothyronine on the Electrophoretic DisTRIBUTION OF L-THYROXINE-I131 IN SERUM

$\mathrm{T}_{3}$ represents added L-triiodothyronine, $T_{4}$ represents total serum L-thyroxine. In each instance, a continuous recording of the radioactivity on the paper strip (lower portion) is compared with the stained protein components on the same paper strip (upper portion). The single arrow denotes the point of application of serum to the paper; the double arrow, labeled "BG," represents background radioactivity. (Buffer: sodium barbital, $\mathrm{pH} 8.6$, ionic strength 0.1.) 


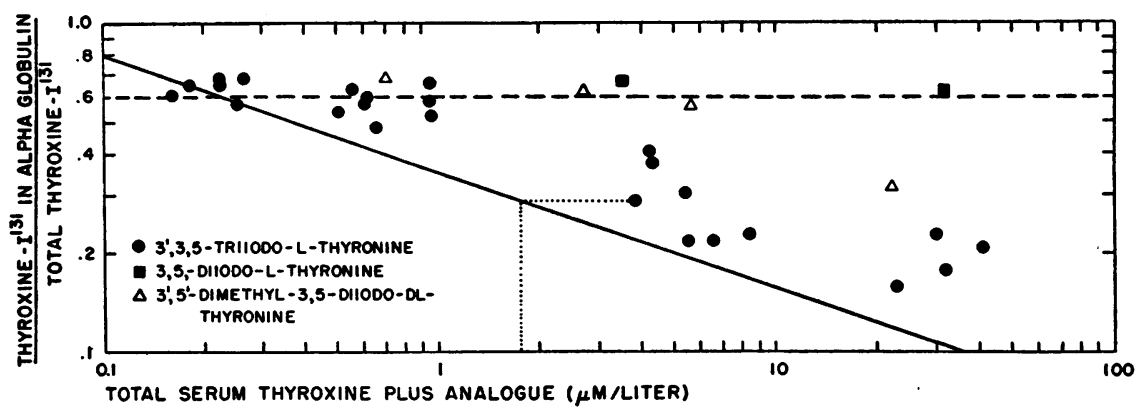

Fig. 2. Displacement of L-Thyroxine from Serum Alpha Globulin by Thyroxine Analogues

The solid line was statistically derived from data obtained with L-thyroxine alone (3). The points represent thyroxine-analogue mixtures in which the total thyroxine concentration was between .06 and .17 micromole per liter. The dashed line indicates the lower limit of thyroxine in alpha globulin at normal thyroxine levels and in the absence of thyroxine analogues. The dotted line indicates the manner in which $\left[\mathrm{T}_{4}\right.$ (Theoretical)] was determined (see text).

The other analogues tested either resulted in similar displacement patterns, or were without effect on the thyroxine- $\mathrm{I}^{131}$ distribution. The molar concentrations required to produce a given displacement of thyroxine, however, were variable.

Data obtained in the earlier study with thyroxine alone (3) were used as a basis for comparison of the various analogues tested. An illustration of the manner in which these comparisons were made is provided in Figure 2. The fraction of the total thyroxine- $\mathrm{I}^{\mathbf{1 3 1}}$ in the alpha globulin area is plotted against the molar concentration of serum thyroxine (endogenous plus exogenous), plus the molar concentration of thyroxine analogue, on logarithmic coordinates. The solid line is equivalent to the statistically derived curve fitting the thyroxine data (at high concentrations) in the earlier study (3). It here takes the form $\log \mathrm{Y} / \mathrm{X}=\mathrm{A}+(\mathrm{B}-1) \log \mathrm{X}$ (where $\mathrm{Y}=$ thyroxine concentration in alpha globulin, $\mathrm{X}=$ total serum thyroxine concentration). The points in Figure 2 represent the data obtained with three thyroxine analogues. It is apparent that L-triiodothyronine is less effective than L-thyroxine itself in producing displacement of thyroxine- $\mathrm{I}^{131}$ from alpha globulin, while Ldiiodothyronine is without effect at the concentrations employed. The $3^{\prime}, 5^{\prime}$-dimethyl analogue of DL-thyroxine exhibits an intermediate effect.

The dotted line in Figure 2 indicates the method of interpolation which provided an estimate of the total concentration of L-thyroxine,
$\left[T_{4}\right.$ (theoretical)], required to produce a degree of displacement equal to that actually produced by the analogue. The ability of the analogue to produce displacement was then compared to Lthyroxine by the expression:

$$
\frac{\left[\mathrm{T}_{4} \text { (theoretical) }\right]-\left[\mathrm{T}_{4}(\text { actual })\right]}{[\text { analogue }]} \times 100,
$$

where the brackets indicate molar concentration. This calculation was made for each of the serum mixtures which fulfilled two criteria: 1) [analogue] was greater than $\left[\mathrm{T}_{4}\right.$ (actual)] by at least two-fold, and 2) the fraction of thyroxine$\mathrm{I}^{131}$ in alpha globulin was less than 0.6. The averages of the calculated values for each analogue are recorded in Table I. Inasmuch as the ability of an analogue to cause displacement of L-thyroxine is in all likelihood due to competitive binding of the analogue itself to TBP, these values are listed under the heading, "Relative Binding Intensity." ${ }^{\circ}$

\section{DISCUSSION}

Certain considerations must be taken into account in evaluating these calculated values for relative binding intensities. First, the variations obtained in individual measurements with the same analogue are considerable. This is indi-

6 References to the affinity of thyroxine analogues for TBP throughout this paper refer only to binding at the thyroxine-binding sites on this protein. 
cated by the fact that the relative binding intensity for individual measurements with L-thyroxine itself ranged from approximately 50 to 150. (The scatter of the individual points around the straight line is shown in the previous study [3].) Second, the apparent affinity of a compound for TBP may be affected by any difference between it and L-thyroxine with regard to binding by other serum proteins. For example, a compound which is bound only by TBP would be likely to have a higher concentration of unbound compound than would thyroxine at comparable serum levels. Since binding to protein is proportional to the concentration of the unbound compound rather than to the total concentration, the value for "relative binding intensity" would be falsely high. Information bearing on this question is available only for triiodothyronine $(4,7)$, and it appears that triiodothyronine may be bound less strongly to albumin than is thyroxine. Thus, the values recorded in the table must be considered as approximations.

Nevertheless, the data permit certain tentative conclusions. The affinity of D-thyroxine (Table I, No. 2) for TBP does not appear to differ significantly from that of L-thyroxine (Table I, No. 1). None of the other analogues tested has a binding intensity as great as that of L-thyroxine itself, but a number of them demonstrate a considerable affinity for TBP. When those analogues with changes only in the $3^{\prime}, 5^{\prime}, 3,5$ positions are considered (Table I, Nos. 3-7), it appears that one or more substituents in the $3^{\prime}, 5^{\prime}$ positions are essential for binding ( $c f$. diiodothyronine-Table I, No. 4). This substituent, however, need not be iodine. Comparison of the $3^{\prime}, 5^{\prime}$-dimethyl and the $3^{\prime}, 5^{\prime}$-dinitro analogues suggest that substitution with the polar nitro groups produces stronger binding and, indeed, the tetranitro-analogue of thyroxine exhibits minimal binding activity. The different configurations of these compounds are unlikely to be a factor in view of the similarity between $\mathrm{D}$ - and L-thyroxine.

Replacement of the phenylalanine side chain of L-triiodothyronine with acetic acid (Table I, No. 9) does not entirely destroy binding, but weakens it greatly. Somewhat surprising is the result obtained with compound No. 8, which appears to indicate that alteration of all of the end groups of thyroxine still permits a considerable degree of binding to TBP. In the remaining analogues of Group A, the alterations in the molecule are too complex to permit interpretation at the present time.

Neither L-diiodotyrosine nor its analogues (Table I, Group B) are capable of displacing Lthyroxine from TBP at the concentrations tested.

While the role of TBP in thyroid physiology has not been established, it has been suggested that the difference between thyroxine and triiodothyronine with respect to binding to this protein may account for at least part of the observed differences in their in vivo effects (4). One of these in vivo differences is the much faster disappearance of intravenously administered triiodothyronine from the circulation (8-10). Similarly, it might be considered that the great rapidity with which injected diiodotyrosine disappears from the blood $(11,12)$ is due to its low or absent affinity for TBP. D-thyroxine, however, disappears with equally great rapidity from the blood (8), despite an affinity for TBP comparable to that of L-thyroxine. Consideration of D-thyroxine, which binds strongly to TBP but has little or no L-thyroxine-like metabolic effects (13) and L-triiodothyronine, which binds relatively weakly but has potent L-thyroxine-like effects, suggests that the molecular features responsible for binding to the serum protein are different from those concerned with metabolic activity.?

\section{SUM MARY}

A series of 14 analogues of L-thyroxine have been studied with regard to their ability to displace L-thyroxine- $\mathrm{I}^{131}$ from its specific binding protein in human serum (TBP). The technique of electrophoresis in filter paper (barbital buffer, $\mathrm{pH}$ 8.6) was employed. Earlier studies with Lthyroxine alone have been used as a basis for comparison, and the "relative binding intensities" of the analogues for the thyroxine-binding sites on TBP have been calculated.

Of the compounds tested, only D-thyroxine has a binding intensity as great as L-thyroxine.

7 The D-thyroxine used in this study is from the same lot that had been tested earlier for turnover in the blood (8). It had also been checked for L-thyroxine-like effect by the goiter prevention assay, and had approximately 10 per cent of the activity of an equimolar dose of L-thyroxine (14). 
Lesser degrees of binding are exhibited by analogues with changes in the $3^{\prime}, 5^{\prime}$ positions, such as L-triiodothyronine and the dinitro and dimethyl analogues of thyroxine. Binding is also retained by certain thyroxine analogues with changes in the phenolic hydroxyl, amino, and carboxyl groups. A number of analogues, including Ldiiodothyronine and L-diiodotyrosine, fail to displace L-thyroxine from TBP in the concentrations employed.

The results obtained with certain of the compounds suggest that the molecular features of thyroxine responsible for binding to TBP are different from those concerned with metabolic activity.

\section{ACKNOWLEDGMENTS}

The authors wish to express their thanks to Dr. Rulon W. Rawson for his most helpful interest throughout this work, and to Miss Helen Hagopian for excellent technical assistance.

\section{REFERENCES}

1. Gordon, A. H., Gross, J., O'Connor, D., and PittRivers, R., Nature of the circulating thyroid hormone-plasma protein complex. Nature, 1952, 169, 19.

2. Silver, S., The nature of the blood iodine and its determination. J. Lab. \& Clin. Med., 1942, 28, 329.

3. Robbins, J., and Rall, J. E., Thyroxine-binding capacity of serum in normal man. J. Clin. Invest., 1955, 34, 1324.
4. Deiss, W. P., Albright, E. C., and Larson, F. C. Comparison of in vitro serum protein binding of thyroxin and triiodothyronine. Proc. Soc. Exper. Biol. \& Med., 1953, 84, 513.

5. Robbins, J., and Rall, J. E., Studies on the thyroxineprotein complex of serum. J. Clin. Endocrinol. \& Metab., 1954, 14, 772.

6. Horst, W., Transport und Bindung im Serum. Untersucht mit Papierelektrophorese und Radioaktiven Indicatoren ( $\mathrm{Fe} 55 / 59, \mathrm{Cu} 64$, Co 56/57, Mn 52, Ga 67, S 35, I 131). Klin. Wchnschr., 1954, 32, 961.

7. Robbins, J., and Rall, J. E., Unpublished data.

8. Rall, J. E., Robbins, J., Becker, D., and Rawson, R. W., The metabolism of labeled L-triiodothyronine, L-thyroxine and D-thyroxine. J. Clin. Invest., 1953, 32, 596.

9. Rawson, R. W., Rall, J. E., Pearson, O. H., Robbins, J., Poppell, H. F., and West, C. D., L-triiodothyronine versus L-thyroxine. A comparison of their metabolic effects in human myxedema. Am. J. M. Sc., 1953, 226, 405.

10. Sterling, K., Lashof, J. C., and Man, E. B., Disappearance from serum of I131-labeled L-thyroxine and L-triiodothyronine in euthyroid subjects. J. Clin. Invest., 1954, 33, 1031.

11. Albert, A., and Keating, F. R., Metabolic studies with I181 labeled thyroid compounds: Distribution and excretion of radiodiiodotyrosine in human beings. J. Clin. Endocrinol., 1951, 11, 996.

12. Tong, W., Taurog, A., and Chaikoff, I. L., The Metabolism of I131-labeled diiodotyrosine. J. Biol. Chem., 1954, 207, 59.

13. Reineke, E. P., and Turner, C. W., The relative thyroidal potency of 1- and d,1-thyroxine. Endocrinology, 1945, 36, 200.

14. Money, W. L., and Rawson, R. W., Unpublished data. 